NEUROSES AND PSYCHOSES.

M. J. asks for references to the subject of the milder neuroses and psychoses and their management. He would probably find nearly al from the third German edition by Dr. E. E. Mayer. Second edition. (London: J. B. Lippincott Co., 1904, 2rs.) which was reviewed in the BRITISH MEDICAL JOURNAL of July gth, 1904, p. 75 ; about a fourth of the work is occupied with a masterly treatment of the subject. The bably also prove serviceable.

\section{SOYA ELOUR.}

IANARK.-Professor Saundby, in his Lectures on Renal and Urinary Diseases, 4 th edition, page $36 x$ gives the following: "The use of soy beans was advocated some years ago by Dujardin-Beaumetz. These resemble the haricot bean, and are obtained from soya hispida. a plant originally brought from China and Japan, but now cultivated in Austria. When
originally introduced it was recommended on the ground that it conoriginaly introduced it was recommended on the ground that it con-
tains only 2 per cent. of starch, but this statement is very misleading,
as is shown from the following analysis by Professor Kinch, given in Professor Frankland's Agricultural Chemistry, which I have had verlfied:

\section{Water ... Analysis of Soy Beans.}

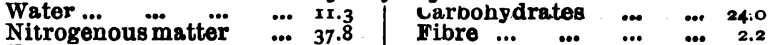

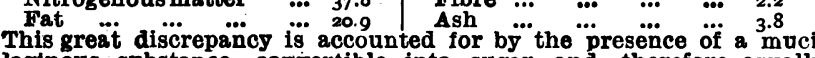
laginous substance, convertible into sugar, and therefore equally obnoxious to a diabetic. Articles made trom this bean should not therefore, be allowed to patients on atrict diet, but those on a modified diet may take them if they like. Some of my patients have disliked the bowels."

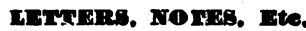

ACUTR POTSONING BY $\triangle$ BINGLE CASTOR-OIL SRRD.

DR. R. B. WRIGHTSON (Aldeburgh, Buffolk) writes to say that he thinks the man whose case Dr. Gordon Gullan described on May 6th cannot have eaten a castor-oil seed but probably one of croton tiglium which resembles it. The symptoms described would point much more to croton-oil poisoning than to any recorded effects from eating castor-oil seeds. As for the latter, Dr. Wrightson has seen seven boys and girls emplojed in shelling castor-oil seeds in a local factory who have eaten castor-olr seeds. Although some of them ate five or six at a time, none of them experienced any worse effects than one would expect from a dose of castor oil. As for the taste. Dr. Gullan's patient said the seed which he ate burnt his mouth and throat a little and made his eyes water; tout Dr. Wrightson has himself tasted castor-oil seeds, and found they have an agreeable nutty flavour. It was because they liked the taste tioned on the point, said they had no burning taste.

MAJOR G. H. FINK, I.M.8. (Retired), in the course of two further communications on the same subject, reiterates his belief that castor-oil seeds in the tropics are unrivalled as a medicine for children as well as tification of the offending seed by the patient, but should prove that it is one of castor oil by testing the solubility of the oil in glacial acetic acid and in alcohol.

*** On reference to page $x 299$ of this issue the writers will find that the beans in question have been identified, and that some references to researches into their poisonous character are given. The correspondence must now close.

IN the title of an article on the Medical Profession in Portugal which 2ppeared in the BRITISH MEDICAL JOURNAI of June 3rd, the author, Professor Miguel Bombarda, of Lisbon, Was erroneousiy described as the editor of Lisboa Medica. The name of the journal, of which our disregret the mistake, which was due to pure inadvertence.

BABIES AS AN IRVRSTMENT.

IN ancient Rome the Mother of the Gracchi proudiy exhibited her boys as her jewels. In Ameriea a mother will in future, if she likes, be abile to put a definite ralue on her offspring in terms of money, and if she is American Mothers' Birth Insurance Company has been, it is announced, American Motherg' Birth Insurance Company has been, it is announced, preminm of in a married woman, on becoming the mother of a living preminm of 128. a married woman, on becoming the mother of a living chenty-eighth, 680 ; and after the thirtv-seventh. $f 100$. It is stipulated that eighteen months must elapse between the births in any one iamily.

DigT DURING Lactation.

R. G. B. JACOBI (Kensington, W.) writes : I belleve that the percentag of mothers physically incapable of suckling would be considerably during the lactation period. Being struck by the number of mothers inlants to the Children's Hospital who stated that they ir milk after a few weeks or months, I made it a rule to ask them about their diet, and found that almost invariably the had made no attempt to obtain a diet likely to influence the production of milk, neither did they appear to understand the importance of this It was, therefore, evident that the person who had delivered them-be it doctor or a midwife - had not suffietently instruoted them on this point. Having visited many hundreds of working-class homes in London, have had a good opportunity of seeing what their diet 1s. Although I I found that the mother and ohildren generally dined off a ster made of some inferior scraps of meat and a large proportion of auet. or some of some inferior scraps of meat and a large proportion of suet. or some the curses of the British people. The other meals consisted chiefly of tea and broed and butter. For a woman to produce any milk on suoh a diet I consider a physical impossibility. Besides a liberal ordinary mixed diet, a suckeling woman ghould drink at least a quart of mill a dav. May, I take this opportunity of asking: How has the peculia 1allicy arisen that a child I8 months old is believed unable to digest meat, even if finely minced? I found that among the working classes children under 3 years of age were seldom given any meat at all, but were stuffed with potato and an apology for gravy; and
have even found among the children of the well-to.do.

MODERN SURGERY.

DR. JOHN BADDON (Hawick, N.B.) writes: The publicity which has been given to the strong language used with regard to modern surgery by the late Prince Bismarck's physician deserves notice by the British so far as I know, to criticize the practice of some surgeons in their precipitate use of the knife, as the oply remedy in many cases which ought not to be interfered with by the surgeon at all; but perhaps the physician is as much to blame as the surgeon. I remember (about the year 1866) that Professor Hughes Bennett, in a case of intestinal obstruction, called a surgeon and said, " The physician has done all he can for this case; open the abdomen and remove the obstruction." The surgeon refused to do so. Then it was against all the principles of surgery. Now these principles have been entirely changed, and no cavity is safe from the onslaught of the surgeon. Former surgeons might be wrong in not acting upon the advice of physicians, but now, in too many cases, they are never consulted, and the very existence of the physician is threatened. Such confusion calls for inquiry, and it is a subject discussed at the annual meeting ai leicester.

THE LOCUM TENENS OF TO-DAY.

Dr. HENRY WATre (Armley, Leeds) writes: I suppose, as the medical man of the future is not to be a general practitioner, according to the ut a sanitar adviser and preventive medicine expert at 6300 a year-paid, like most things appear
to be, from the rates-training in the routine of general practice and the thousand-and-one detalls that were taught under the good old apprenticeship system is unnecessary and futile. I deplore it much. I received my medical education, such as it is, from two sources, both indispensable and each complementary to the other - my hospital training, or the scientific side, and my apprentieeship or management teaching. The result of a purely hospital training is not to the advantage of the public nor to the practitioner, and the result is seen in the type of week and railway fare; who treats one's patients with the asperity of an overworked house-surgeon, breathes aggressive surgery at every pore, shirks all dispensing and dressings. All his ducks are medical or surgical swans; his dyspepsias are all reoommended gastro-enterostomy,
and his colics removal of the appendix or some portion of the abdominai anat omy, and every surgical case is urged to enter a public or private hospital, leaving the unfortunate general practitioner the doubtful privilege of telephoning there twice aday to allay the anxiety of anxious friends. And it is to this modern type of medical we unhappy practitioners have to look for our annual holiday. Small wonder we have reduced it to its minimum whilst these irresponsible and light-hearted gentry patients ; and the lesson that complaints are most simple, and not of patients; and the lesson that complaints are most simplo, and not of necessity serious; and that
will still effect many cures.

\section{A Prouliar Cask of Hetterophthalmos.}

CAptain ALFRED J. HULL, R.A.M.C. (Shansi, India) writes: In describing his interesting case of heterophthalmos Mr. Feldman (BRITISH MEDICAl JOURNAL, April 22nd, p. 882) appears to have expected to find the pupils unequal on account of difference in the colour of the irides; and ingenulty, when a simple anatomical explanation would have sufficed. ingenuity, when a simple anatomion explanation would have sumiod. is admitting more light than the dark, then by consensual action the reaction to light takes place in both pupils in the same way. From the retina of each ese fibres pass partly to the right and partiy to the left optic tracts. From these the stimuli are transmitted to both right and own eye. The consensual reaction is really as direct as the reaction to stimuli of the iris direct. As a matter of fact, the light is not cut off by the coloured portion of the iris but by the opaque posterior pigment of more effect upon the contraction of the pupil than the colour of the paint on a pantechnicon van will affect the furniture inside.

The Phrasiocogit of Progrmss.

A LRCTURBR on English at an American college for ladies, in discourging to the wise virgins of his class, happened to refer to the period tha extonds "from the cradle to the grave." After uttering these words he obsolete phrase. There are no more cradles, and soon there will be no more graves. The modern form should be, from the bassinet to the crematory."

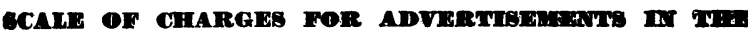
BRTMISF MEDICAI JOURNAI.

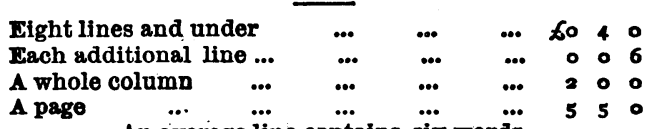

An average line contains $\ddot{\text { six }}$ word̈s.

Advertisements should be delivered, addressed to the Manager, at the Office, not later than first post on Wednesday morning preceding publication; and if not paid for at the time, should be accompanied by a reference.

Post-Office Orders should be made payable to the British Medical Association at the General Post-Office, London. Small amounts man be paid in postage-stamps.

N.B.-It is against the rules of the Post Office to receive letters ax Postes Restantes addressed eithor in initials or numbers. 